\title{
Research on the Present Situation, Problems and Countermeasures of Flipped Classroom in English Teaching of Colleges and Universities
}

\author{
Zhan Weihua \\ Xi"an International University, Shaanxi Xi'an, 710077
}

Keywords: colleges and universities; English Teaching; flipped classroom

\begin{abstract}
Based on the basic connotation and characteristics of flipped classroom teaching model and combined the current situation and existing problems of flipped classroom teaching activities in colleges and universities, this paper probes into the optimization strategy and implementation method of this teaching model. The purpose of this study is to improve the application of flipped classroom teaching model in English teaching of colleges and universities, and to ensure the effectiveness and practicality of the teaching.
\end{abstract}

\section{Introduction}

As an important part of English teaching in universities and colleges, English is one of the courses that the teachers and students feel difficult to teach and learn. Especially in oral expression and comprehensive grammar learning, many students have shown the problem of lacking learning motivation and learning inefficiency. As the constant development of the times and the trend of economic globalization is becoming increasingly prominent, it has put forward higher requirements for talents' English ability, while the traditional English teaching model of universities ad colleges can not meet the objective needs of students. Under this background, the flipped classroom teaching model is introduced into universities and colleges' English teaching with its unique learning model and value. In order to give full play to the effect of flipping classroom in English teaching of colleges and universities, the definition and characteristics of this teaching model are analyzed as follows.

\section{Present situation of flipping classroom}

\subsection{Definition of flipping classroom}

Flipping classroom is in fact a special teaching model from the West. The basic viewpoint of the model is to solve some problems in the traditional teaching model by inverted way. For example, in the traditional teaching model, students do homework in the evening, participate in the classroom in class and listen to the teacher during the day. In the flipping class, students learn new knowledge and skills independently, interact with teachers in class and complete homework tasks. In this way, it not only subverts the traditional teacher's high position in the classroom, but also effectively solves the problem that the students' enthusiasm is not strong enough to participate in the study, and effectively arouses the initiative of learning. It is worth noting that the flipped classroom teaching model introduces the concept of teacher-student interaction and transforms the classroom into a more flexible place for learning and communication, so that students' scope of knowledge and learning area can be effectively expanded, and the learning efficiency can also be improved accordingly, this is the unique advantage of the flipping classroom teaching model.

\subsection{The current situation of the application of different types of flipped classroom models}

From the dimension of time, the flipping classroom allocates the time to the students for learning new knowledge by them own, especially some simple knowledge and contents can be learn directly by self-study. In this way, teachers need not to explain some simple knowledge in class teaching, which improves the efficiency and effect of teaching. In addition, the invert of time is also reflected 
in the increase of opportunities for students to learn independently, the students not only need to complete the tasks delivered by teachers, but also need to interact with teachers and other students in class so that they could improve the efficiency of time utilization.

Another prominent feature of the flipping classroom is the invert of status. As we all know, in the traditional classroom teaching activities, teachers have a very critical position. In most cases, teachers will teach according to their own syllabus, but rarely adopt students' opinions and suggestions. In the long run, students will become accustomed to learning according to teachers' teaching habits and ways, and even lose enthusiasm for active learning. But in the model of flipping classroom, students must learn before or after class, and then exchange their point of view with their teachers and classmates in class; this also improves the status of students in class to a certain extent and realizes the invert of status in class.

The traditional teaching model pays too much attention to the basic knowledge itself, and teachers often need a lot of time and energy to explain the basic knowledge, which is a waste of time for many students who master the basic knowledge very well. As the development and application of flipping classroom, the basic teaching model has been changed. Students learn by their own according to their own learning conditions, and then teachers organize explanations and classroom exchanges, so the teaching links become smoother and highly targeted. In addition, the process of learning knowledge at home is also a process that the students can digest all the knowledge systematically, which is more efficient and effective than the traditional classroom teaching.

\section{Problems existing in the implementation of the flipping classroom in English teaching of colleges and universities}

\subsection{Formalism is serious in flipping classroom}

The flipping classroom teaching model itself has many advantages, but in the process of implementation, teachers often have insufficient professional quality and serious problems of formalism in class. Especially at present, many teachers are still influenced and restricted by the traditional teaching model when they change their teaching model, and even the teaching assessment model of the school itself remains within the framework of the traditional teaching model. As a result, teachers can only complete their teaching tasks according to the original assessment system, which is obviously not conducive to show the effect of flipping classroom teaching model.

\subsection{Teaching condition is insufficient}

According to the investigation situation, at present, very few of the major domestic colleges and universities are equipped with special video recording facilities. Because of the inherent shortage of teaching conditions, and many teachers do not have the experience and habits of video recording, so some teachers must learn the new teaching model completely by their own before they teach their students. In addition, in most cases, there are about 40 students in a class of the colleges and universities, if the flipping classroom is applied in such a large number of students, it is also prone to the problem of insufficient communication in the class, it limits the teaching result of this teaching model.

\subsection{The limitation of students' Learning ability}

The limitation of students' learning ability is also a very serious factor. From the objective point of view, most students enter university from high school, their study habits and patterns stay in the original state, and can not be changed in time. In addition, many students in high school have the problem of tending to go overboard on one or some subjects, and their English learning ability is also relatively poor, these will affect the teaching effect of the final result of flipping classroom, and even lead to some students' self-learning frustration. 


\section{Optimistic countermeasures for flipping classroom of English teaching in colleges and universities}

\subsection{Pay more attention to the application of multimedia technology}

As the development of the times, the application of multimedia technology in modern educational activities has become very common. In the process of playing multimedia resources, the students' attention can be attracted and the abstract knowledge can be explained better. Some teaching materials can also play a auxiliary role, the teachers should introduce more educational resources to the teaching activities, so that the students can take advantage of the materials at any time. For most students, much knowledge can not be learned once or twice, it needs repeated learning until the students master the knowledge well, and the application of multimedia technology is a good solution to this problem. In the traditional model of English teaching, due to the relatively scarcity of learning materials, many knowledge can not be updated, and the new ideas of the topics are less, which often lead to boring situations in class, especially in the review class, this problem is more serious. In the flipping classroom, by the video material study, the students can better complete the self-study tasks their teachers assign to them, even they can make some video records in order to show their study results, these have good effect on the exchange of learning experiences between teachers and students, and the improvement of learning effect.

\subsection{Implementing group teaching}

Group teaching is a kind of teaching model commonly used in flipping classroom. Before implementing this model of teaching, groups should be divided in advance to create circumstances by guiding students to watch videos and discuss in groups. In the whole discussion segment, the democratic opinions of the students should be respected. The teachers should not express their views as much as possible. Instead, the discussion results in each group could be presented by the group leader, and the different results should be discussed in class. If there are results that can't be reached an agreement in class, the teachers and students can also check the relevant information after class. For example, in some special courses, the teachers can ask the group to prepare their own ideas in ten minutes, and then let the team leader report on the results of the discussion, or show the results directly. Finally, the final conclusions are obtained by teachers' comments and group reviews, which can also be corrected effectively by the teachers when the results have some expressive mistakes. For example, in the course of about "Love", after watching the video, I asked the question to my students ---- "how do you understand familial affection?" Then the groups discussed the "love" in the family and the "love" in the society, which was concluded by the students after ten minutes. In this way, they can not only conclude their ideas better, but also improve their oral English and listening skills inadvertently.

\subsection{Strengthening the guidance of the teachers.}

On the surface, the flipping classroom reduces the teachers' teaching burden, and it can usually complete the teaching tasks only by completing the basic classroom guidance. In fact, the appearance of flipping classroom model puts forward higher requirements to the teachers who must use the spare time to complete the planning work of teaching guidance, so as to improve the efficiency of students' communication in class. At the same time, how the students to learn at home, this question often need the guidance and supervision of the students to some extent. In the process of strengthening teachers' guidance, we should first pay attention to the teachers' own professional quality and ability, so that they can express more contents in a more limited time. Secondly, we should help students to understand the text more correctly and effectively. The explanation should be concise, and the text can not be interpreted excessively, nor can be insufficiently analyzed. Finally, to strengthen the guidance of teachers, we can combine the cultural background of teachers to expand some aspects of knowledge. For example, in the course of American culture, teachers can share some foreign stories and their own learning experiences, by this way, to close the relationship between students and teachers, and then to improve the teaching effect. 


\subsection{Perfecting classroom assessment}

Classroom assessment is also of great significance to improve the effect of flipping classroom teaching. In most cases, the classroom assessment should choose the discourse of encouraging nature to the students, by encouraging the students to reduce the burden of their learning as much as possible, so that they have more time and energy to spend in the flipping classroom teaching. Of course, if the students have disputes and mistakes in the classroom discussion, teachers should also actively guide them and correct the mistakes, especially for some typical mistakes should be explained emphatically. In the assessment of flipping classroom teaching in schools, we can not only focus on the marks, but also should consider the students' learning stage, their learning state and classroom atmosphere to carry out comprehensive assessment. These have certain help for taking the best use of the teaching value of flipping classroom.

\section{Summary}

To sum up, the key to the effective implementation of the flipping classroom teaching model is the free atmosphere in the classroom and the ability to realize the transformation of the roles of the students and the teachers in the class. By the flipping classroom teaching model, the students can get more time to complete the work of their own, and the classroom is not the only place where the students can learn knowledge, and they spend most of the time in class in communicating with others in English so as to effectively prevent the situation of "Dumb English". In order to strengthen the application of the teaching mode of flipping classroom, it is also necessary to pay attention to the multimedia technology and the grouping teaching, strengthen the teaching effect by means of the teacher's guidance and the design of the assessment of the teaching in class, and finally improve the students' English practice ability and exercise their oral and comprehensive English abilities.

\section{References}

[1] Yin Donghua. Calm Deliberation on the Hot of Flipping Classroom at Home and Abroad: Demonstration and Introspection [J]. Journal of Research on Education for Ethnic Minorities, 2016, 27(01):25-30.

[2] Wang Tingting. Research and Analysis on the Value of Flipping Classroom in College English Teaching [J]. English Square, 2016(04): 111-112.

[3] Lv Tingting. A Research on College English Autonomous Learning Model Based on Flipping Classroom [J]. Foreign Languages in China, 2016, 13(01): 77-83.

[4] Deng Di. A Review on the Application Research on Flipping Classroom Teaching Model in College English Teaching [J]. Foreign Language World, 2016(04): 89-96. 